\title{
Cultural Safety Circles And Indigenous Peoples' Perspectives: Inclusive Practices For Participation In Higher Education
}

\author{
Johnnie Aseron, Southern Cross University, Australia \\ S. Neyooxet Greymorning, Southern Cross University, Australia \\ Adrian Miller, Griffith University, Australia \\ Simon Wilde, Southern Cross University, Australia
}

\begin{abstract}
Indigenous experiences, as found within traditional ways and cultural practices, are an acknowledgement of traditional methods for sharing, learning, and collective knowledge development and maintenance. The application of Cultural Safety Circles can help provide a collective space where definitions for cultural and educational exchange can take place and be identified. It is through this application that a discussion is presented on how the inherent issue of cultural safety, as it pertains to participation in higher education, can be explored to a deeper understanding.
\end{abstract}

Keywords: Indigenous Higher Education Participation; Cultural Safety; Cultural Safety Circles; Indigenous Led Research

\section{INTRODUCTION}

R ecently, in recognition for the continuing need to address the economic, social and educational disparity between Indigenous and non-Indigenous populations in Australia, an investigation was undertaken that focused on community identified understandings of key barriers and obstacles pertaining to sustained participation in higher education by Indigenous populations (results of which are discussed in Aseron, Wilde, Miller and Kelly, 2013). Our initial investigations revealed the need to first identify a manner that would include a safe cultural methodology imperative to engendering this participation. It soon became evident that current levels of understanding surrounding issues and ideas about acculturation, inclusiveness and multiculturalism remained barriers to participation in higher education for many Aboriginal and Torres Strait Islander as well as nonIndigenous Australians.

The ensuing 'higher education participation for Indigenous Peoples' conversations required a secure platform to develop as well as investigate, with community participation, current understandings of higher education, past recognisable efforts and thoughts for what might work for future attempts. With these ideas in mind, our early investigative attempts necessitated an understanding of what comprised and created cultural safety.

With an increasing number of publications from both institutional and governmental organisations raising questions regarding cultural awareness or sensitivity practices, many researchers have begun to attempt a description of cultural safety (Edwards et al., 2007; Wilson, 2006; Graveline, 2000). Models or methods for attaining such competency and/or best practices for achieving cultural safety within higher education, however, remains as yet an unresolved issue.

Whilst there is growing evidence with regard to cultural safety and cultural competency gaining attention as an avenue for research and comment (Ramsden, 2002; National Aboriginal Health Organisation, 2008), very little extant literature exists that describes a methodology necessary to achieve such a desired state. Further, pre-existent Indigenous Peoples' cultural definitions of methodology for achieving cultural safety and/or competency are varied 
in their approach and, rightfully so, are dependent on Tribal customs and affiliations. Even where commonalities and practices can be identified as being shared, care must be taken so as not to engender any presumptions in delivery of practice and method, or the understanding of practice and method, which can arise when utilising Indigenous Peoples' culturally specific models. Simply put, one of the thoughts informing the nature of the research was to ask the question, "Are there current understandings and ideas for a collective, identifiable method to both assure and create cultural safety with respect to higher education participation by and for Indigenous populations?" The goal of this paper, therefore, is to discuss the need to both recognise and develop current and relevant methods and models for an equitable and shared definition of the process or processes needed to achieve cultural competence and cultural safety.

\section{RESEARCH OVERVIEW AND LITERATURE}

As defined in the UN Millennium Declaration (September, 2000), the Millennium Development Goals (MDG's) raised issues for the input and inclusion of Indigenous Peoples within the development debate. Since that time this debate has produced other key documents including the UN Declaration on the Rights of Indigenous Peoples (September, 2007) and, more recently, the UN State of the World's Indigenous Peoples report (2009). Within this report are some key issues recognised as important to better integrate issues for Indigenous Peoples into MDG goals, policies and programmes. "Policies must be put in place to insure that Indigenous Peoples have universal access to quality culturally-sensitive social services. Some areas of particular concern are intercultural/bilingual education and culturally sensitive material..." (UN State of the World's Indigenous Peoples, 2009: 40). This report exemplifies the continued use of the ideas of cultural awareness and cultural sensitivity, which assumes methodology, as well as practitioners, that are conversant in such a method. Further, Ramsden (1992) explains that cultural safety is achieved from a continuing process that moves from cultural awareness (input) to cultural sensitivity (competency) and finally cultural safety/security (outcome). Despite the plethora of ideas surrounding cultural awareness, sensitivity or safety, little identifiable literature exists that links methods to achievement or desired outcome. These efforts, therefore, were an attempt for a practical analysis of processes, which is suggested by the absence of current established models unencumbered by preconceived or presumed knowledge (Running Wolf \& Rickard, 2003).

In response to the Bradley Review (2008), the Australian Federal Government enacted the Higher Education Participation and Partnerships Program - an initiative designed to increase higher education engagement for low socio-economic groups. Developing innovative methods for research, appropriate and inclusive of diverse cultural backgrounds, is critical to understanding the 'stakeholder' view, in both participation and resultant consultative forums (Aseron \& Malkin, 2006).

Broadening this understanding within a consultative process, for many tribal groups an important tool for preserving their cultural identities has been through a tradition of oral narratives. With regard to the tradition of oral narratives, where Lakota Elder Luther Standing Bear expressed how "stories were the libraries of our people" (1933), others posit storytelling as a flexible method of education (Beck, Walters \& Francisco, 2001). Thus, the story, as narrative (and educational tool), is not a new cultural platform as it has historically provided the people with a vehicle through which many things were learned. Through story, the world was shaped and given meaning and as the people's world took on meaning, they adopted specific cultural worldviews and practices. The Apache of Arizona express that their stories stalk them in a way that makes an individual think about his or her life (Greymorning, 2004) "They make you remember how to live right, so you want to replace yourself." (Basso, 2000: 59) Greymorning also relates that stories, in addition to what they "say about places, events, morals, or concepts of cultural identity, also carry a message for the person at whom they are directed. Some Apache say that these stories are like arrows causing those they hit to replace themselves - a metaphor for healing." (2004: 13) When imbalances occurred within this meaning, there were culturally safe mechanisms, often through ritual and ceremony that would be performed. Such mechanisms played a major role in how tribal members conducted themselves in culturally safe and appropriate ways. 


\section{THE ORAL NARRATIVE: TALKING, YARNING AND CULTURAL SAFETY CIRCLES}

As previously noted, little extant literature exists as to methodologies for the achievement of cultural safety, nor the models that exemplify the theoretical (Theory vs. Praxis). This is not to suggest there is no evidence whatsoever. Amongst those who have commonly (if somewhat erroneously) been known as the 'Plains Indians' of North America, culturally safe practices were used to reach decisions involving various community governance issues, including areas such as dispute/conflict resolution, justice/judiciary and peace. As with many Indigenous societies, justice was corrective and employed as a measure when any member within the tribe needed reformation to tribal structure. Once this occurred, the individual could then be reincorporated back into the community. The example below discusses such a situation that involved conflict, as well as the resulting desired peace. Dating from the 1840's (long before the reservation system existed on the Plains), this story helps illustrate a classic example of how a delicate matter might be handled, in a culturally derived and safe manner, in order to elicit the best possible outcome.

A group of Cheyenne, while out on a horse raid against the Kiowa and Comanche, had stopped for rest and provisions at a large encampment of their allies, the Arapaho. While there, a group of Apache, who were allies of the Kiowa and Comanche, had gone to the lodge of an Arapaho leader called Buffalo Bull (Heneecee), to inform him that they, the Kiowa, Comanche and Apache, all desired peace with the Arapaho and Cheyenne. Heneecee called for eight Cheyenne to come to his lodge to speak on the matter. When all were assembled he filled his Pipe and offered it. Declining the Pipe, Seven Bulls, who led the Cheyenne war party, said, "Friend, you know that we are not chiefs. We have no authority to smoke to make peace with these men. We can only carry your message and leave it with our chiefs to decide. "As a Cheyenne war leader, he had the authority to call back his warriors so they returned to camp.

When they reached camp he reported the request for peace. The following morning a double-pitched lodge was set up, and when all was in order Seven Bulls and his warriors were sent for to officially present the culturally delicate matter. The chiefs, hesitant to make a ruling, put it before the Dog Soldier Society to decide. High Backed Wolf, the presiding head chief of the Society, sent a runner to get White Antelope and Little Old Man, the bravest chiefs among the Dog Soldiers. After speaking to the two warriors, High Backed Wolf ended with these words: "Now my friends you go and assemble your Dog Soldiers. Tell them about this matter, and talk it over among them. Let us know what ... you think is best to be done."

It was White Antelope who addressed the Dog Soldiers telling them the problem. "The chiefs are leaving this matter to us, because we are the strongest of military groups. It is my own thought that our chiefs are in favor of making peace. What do you now think about this?"... White Antelope and Little Old Man ... returned to the Council Chiefs and told them it was decided to make peace with their enemies. All the chiefs stood up, pleased with the decision (see Llewellyn \& Hoebel, 1941: 92-93).

This particular event, though simplified, displays aspects of tribal diplomacy beyond the speeches and discussions, whilst revealing an understated complexity. Combined with some cultural background and understanding, this becomes more evident. The horse was paramount on the Plains as an object of status. The Kiowa and Comanche were rich with horses, whereas for Cheyenne youth horses presented a path to glory, recognition, and cultural wealth, achieved at times by successfully 'raiding' neighbors' horse stocks without incident (the most desirable when achieved and no mean feat). For the Council Chief's to accept an offer of peace, therefore, other tribal members would consequentially be blocked from one of their resources for acquiring horses. Because hostilities between the Kiowa and Comanche had been ongoing for over 50 years, this was an important and culturally delicate decision that necessitated a discussion within a culturally safe environment, which in itself helps explain why the Council Chiefs were hesitant to resolve the matter on their own. By choosing to give the decision over to the Dog Soldiers, they acted in a culturally inclusive manner, deftly turning the seat of authority for decision-making on its head. Subsequently, once a decision was reached, they then flipped the decision back again to their purview, without a single contentious word. Responsibility moved from the hands of the Council of Chiefs to the Dog Soldiers, from the Dog Soldiers to two of their most celebrated warriors, who then, in turn, were charged with reaching a decision for which the entire nation would ultimately be held. 
The benefit and beauty of this comes with recognising that throughout the decision making process the authority of the Council of Chiefs was never under question! (Which kept them and all the participants in the discussions culturally safe). Once the decision was made, White Antelope and Little Oldman returned and dutifully handed their decision back over to the Council of Chiefs who, after gratefully thanking the Dog Soldiers, then discharged them. When put in motion, the process allowed the Council of Chiefs, as the seat of tribal governance, to neither lose face nor authority. The decision for peace came from the Council of Chiefs and was delivered to the tribe through their highest authority, the Priest-Chief himself. This further inclusion is an example of having policy flow through the tribe's most sacred leader, whereby the decision itself became sacred law for all to follow and participate in maintaining. Thus, a peace between the Kiowa, Comanche, and Apache, made through the Cheyenne and Arapaho in the 1840 s, became a sacred trust that was never broken.

In contemporary terms, among the more recognizable descriptions for these types of cultural mechanisms are those of the 'Yarning Circle' and the 'Talking Circle'. The Yarning Circle description encompasses both modern and historic communal gathering processes found amongst many Australian Aboriginal and Torres Strait Islander populations (Bennet, 2000). Additionally, many people would be familiar with the Talking Circle concept introduced into the Reconciliation movement and adapted from Native American Cultures (Picou, 2000). As in the example above, both descriptions derive from Indigenous Peoples' methods recorded through the stories, songs and ceremonies as mechanisms for inclusion into the transfer of knowledge, participation in the decision-making process and identifying of shared goals and desired outcomes for community. Encompassing all of the aforesaid ideas, along with the singular participatory involvement of the communities involved in the study (results of which are discussed in Wilde, Aseron, Miller and Kelly, 2013), the Cultural Safety Circles (CSC's) foundation began to emerge. CSC's are borne of the Indigenous experience and found within traditional ways and cultural practices. CSC's are an acknowledgement of traditional methods for sharing, learning, and collective knowledge development and maintenance. The application of CSC's can help provide a collective space where definitions for cultural and educational exchange take place and can also be identified. It is through this application that the inherent issue of cultural safety, specifically where it pertains to higher education participation, can then be explored to a deeper understanding.

\section{RESEARCH METHOD/OVERVIEW}

The main aim of this investigation was to explore the need to develop current and relevant methods for an equitable and shared definition of the process or processes needed to achieve cultural competence and cultural safety. A secondary aim was to highlight an Indigenous perspective that would both exemplify and inform ideas relating to theory and practice.

This study identified that this topic is under researched, which presented some further questions; however, what is more significant is the lack of literature surrounding shared definitions of cultural safety, as defined through Indigenous and non-Indigenous paradigms. Creation of an appropriate space, as recognised and defined by community members, as well as service and education providers, is needed to initiate an intersection inclusive of a cross sampling of cultural groups. This inclusivity then becomes essential, if not paramount, to that success.

A mixed-methods approach using qualitative and quantitative methods was used given that qualitative research is generally suited to theory generation and quantitative to theory testing (Parkhe, 1993; Strauss \& Corbin, 1990). The need to discern presupposed experience and assumption surrounding method to achieve awareness of cultural competency and resultant cultural safety is justified.

\section{DATA COLLECTION, ANALYSIS AND DISCUSSION}

Data for this paper derives from three focus group discussions involving 76 participants of whom 34 identified themselves as Indigenous Australian or other Indigenous nation. A further demographic breakdown saw $31 \%$ of participants being male and $69 \%$ female. Due to the exploratory nature of this research, a non-probability sampling approach, specifically a volunteer 'opt-in' sampling strategy (Sue \& Ritter, 2007), was embraced for these discussions. Each group was lead by an experienced Aboriginal Australian Elder and/or academic research facilitator. Focus group discussions lasted approximately 45 minutes. In satisfying the stated research objectives, this 
study further adopted a quantitative instrument administered as both a pre- and post- survey to each focus group member. The nature of the quantitative instrument was to gauge participants' views and understanding as to the notion of cultural safety, both prior to and following detailed focus group discussions involving ideas about cultural competence and safety.

Respondents were asked to provide their level of agreement to ten (10) questions related to ideas of cultural competency and safety practices. Respondents indicated their levels of agreement via a 5-point Likert scale, by assigning a value between 1 (never) and 5 (always) to each question. Questions included (but were not limited to) ideas and statements such as; 'Have you ever spoken about cultural safety with people of your own cultural background?' 'Do you believe that you must first understand a culture different to your own in order to achieve cultural safety/competence?' and 'Do you believe that cultural safety is important enough and should be taught in schools?'

Results of the subsequent quantitative analysis found that two particular questions raised noteworthy responses. For example, when asked 'Do you believe that you are culturally aware?' The difference in pre and post response was recorded as 4.01 and 3.72, respectively (on a 5-point scale), indicating that after (post) the focus group discussions about cultural safety ideas, respondents were potentially challenged on the notion that they initially felt (pre-discussion) that they were 'culturally aware'. An additional question inquired "Do you believe that the cultural safety circle or method allows for the identification of individual and group understanding?", garnishing 3.57 (on the 5-point Likert scale) in the pre-discussion instrument as opposed to a positive increase to 3.97 in the post response. Again, this potentially indicates that following the focus group discussions about cultural safety and methodology, participants were more positive in agreement to the use and implementation of a cultural safety circle, as a methodology to engender both greater understanding and confidence for feeling culturally safe.

While these quantitative indicators add some insight into group participants' current views and understanding about a general idea of cultural safety and cultural safety practice, the qualitative results were highly informative and enlightening to the wider research objectives, with more specific observation on attitudes towards Western paradigmatic educational practices.

One significant theme that arose across the three focus group discussions were ideas and understandings relating to an identifiable method for defining, understanding and achieving a shared sense of cultural safety/competence as relates to higher education and higher education activities. Although there was little to no group consensus for an agreed definition about a shared sense of a methodology appropriate to this investigation (and the achievement of the resultant cultural safety/competence), there was, however, a heightened awareness for the inclusion of some kind of cultural safety methodology, of which cultural safety circles might be considered as appropriate (this discussion seems to be evidenced through the earlier quantitative results as noted above).

Another prominent theme centred on the perceived inherent dangers with the assumption that Indigenous populations view higher education providers, such as a university or education campus, as accessible. It was expressed through the discussions that apprehension exists in working with or going to 'the uni'. The expression of feeling uncomfortable or alienated to a higher education experience was also tied to location, with comments noted about participants having never really had business at a higher education institution (such as a university campus) or understanding 'what goes on there...'

Perhaps this apprehension could be mitigated to a greater or lesser degree by understanding that stakeholder-ship is not engendered by fractured attempts to engage Indigenous populations in one-off or infrequent, unsustained efforts or events. As a consequence, a further theme borne from the discussions was that Aboriginal Australians, in some areas and disciplines, are self-identifying as being 'over researched'. This notion was essentially couched in the perspective that such attempts and approaches by researchers are driven by the research and institutional agenda, as opposed to the needs of the Indigenous populations themselves:

'They only call us when they need to get money' said one Aboriginal Australian male Elder. 


\section{CONCLUSION}

Despite the exploratory nature of this study, researchers found that a divergent understanding exists as to: 1) what is culture, 2) what is cultural safety, and 3) what cultural safety practices can be identified as appropriate for engendering Indigenous participation in higher education. As previously discussed, the distinct lack of extant literature in the area of cultural competence/safety and related methodologies for higher education participation suggests that this current research will add knowledge as an attempt to close this research gap in some key areas.

Within this research effort, a cultural competency or cultural safety methodology investigation can continue with the participation of Indigenous Peoples and non-Indigenous stakeholders, government agencies, nongovernment entities and higher educational institutions contributing significantly to the lack of description and understanding for practice and method found within the current literature. The maintenance of continuity that allows ongoing activity, investigation and development of stronger and deeper levels for identifying, and defining and understanding a cultural safety framework, are also desired outcomes.

There are a number of inherent limitations within exploratory studies, both in institutional understanding and within Indigenous Peoples research paradigms. As one example, Indigenous populations encompass a tribal affiliation system that does not recognise borders in the same manner as their non-Indigenous counterparts, whereby institutional research initiatives are typically constrained to smaller geographical regions that often do not correlate with tribal boundaries. As a further consequence, such Indigenous Peoples research efforts and the subsequent findings may not be applicable to all Indigenous populations as a 'one size fits all' perspective. Therefore, exploration of this lack of connectivity suggests the need to develop larger linkages with both higher education institutions and Indigenous populations.

\section{ACKNOWLEDGMENTS}

Of primary importance, we wish to recognise the interest, support and participation of the various Indigenous populations involved in this investigation, the many 'nations' that include Australian Aboriginal and Torres Strait Islanders, particularly those of the Gumbaynggirr, Dhunghutti and Bundjalung nations, Native Americans and First Peoples of the US and Canada, in particular the Haudenosaunee, Arapaho and Lakota nations; whose input, interest, vision and patience informed the basis, body and purpose of these efforts. We also gratefully acknowledge all of our Elders, past and present, for their wisdom and forbearance in the maintenance of our various cultural ways and practices. Of special note is the input of our late Uncle Harry, whose insight, support and commitment to the community action committee and ideas about higher education for all Indigenous Peoples, shall forever resonate within each of us fortunate enough to have known him. This investigation is an outcome of a project funded through the Australian Federal Government's Higher Education Participation and Partnership Program (HEPPP) through Southern Cross University, NSW.

\section{AUTHOR INFORMATION}

Johnnie Aseron is currently the Lead Project Officer of an Indigenous Community Directed Capacity Building Project, Southern Cross Business School, Southern Cross University, Coffs Harbour Campus, Australia. Along with more than 25 years of extensive work in Indigenous community development programs (including health and wellbeing, education, socio-economic and culturally focused issues), the past few years he has lectured for Gnibi College of Indigenous Australian Peoples (Southern Cross University), whilst engaging in focused efforts for Indigenous led research. E-mail: johnnie.aseron@attglobal.net (Corresponding author)

Professor S. Neyooxet Greymorning is a political anthropologist who has conducted research among Indigenous peoples of the United States, Australia, Canada, Colombia S.A., New Zealand and East Timor. Neyooxet's extensive publications reflect research interests that include the maintenance and restoration of Native American languages, Indigenous sovereignty and contemporary Native American issues, Neyooxet holds positions in Anthropology and Native American Studies as a faculty member at the University of Montana. He is also Adjunct Professor (Division of Research) at Southern Cross University, NSW. E-mail: neyooxet.greymorning @mso.umt.edu 
Adrian Miller is of the Jirrbal people of North Queensland and Professor of Indigenous Research at Griffith University, Australia. Professor Miller has a vast record in researching many areas of health issues that impact Australian Indigenous Peoples and communities. He has Chaired school and community committee's that represent the views of Indigenous families and his experience over the past 16 years in higher education has primarily focused on management, leadership, academic program development and teaching. E-mail: adrian.miller@griffith.edu.au

Dr. Simon Wilde is a lecturer with the Southern Cross Business School, based at Southern Cross University's Gold Coast Campus, Australia. Having recently completed his doctorate, his broader research focus is in the areas of marketing (especially challenges faced by NGOs and public sector entities) and general regional development issues. E-mail: simon.wilde@scu.edu.au

\section{REFERENCES}

1. Aseron, J. \& Malkin, J. (2006). Native Entrepreneurship in South Dakota: A Deeper Look. Northwest Area Foundation. Washington DC: CFED.

2. Aseron, J., Wilde, S., Miller, A. \& Kelly, S. (2013). Indigenous Student Participation in Higher Education: Emergent Themes and Linkages. Contemporary Issues in Education Research 6(4) 417-424.

3. Basso, K. (2000). Wisdom Sits in Places. New Mexico: University of New Mexico Press, 59.

4. Beck, P., Walters, A. \& Francisco, N. (2001). The Sacred: Ways of Knowledge Sources of Life. Tsaile, Arizona. Dine College.

5. Bennet-Mclean, D. (2000) The Yarning Circle. Retrieved from http://www.rilc.uts.edu.au

6. Bradley, D., Noonan, P., Nugent, H., \& Scales, B. (2008). Review of Australian Higher Education: Final Report. Canberra: Commonwealth of Australia.

7. Edwards, T., Smith, J.D., Smith, RJ \& Elston, J. (2007). Cultural perspectives in Australia's Rural and Remote Health: a social justice perspective. Croydon, Victoria: Tertiary Press, 48-72.

8. Graveline, F.J. (2000). Circle as a methodology: Enacting an Aboriginal paradigm. International Journal of Qualitative Studies in Education, 13, 361-370.

9. Greymorning, S. (2004) A Will to Survive (Ed.), Indigenous Essays on the Politics of Culture Language and Identity, Boston, McGraw-Hill, 13.

10. Llewellyn, K.N., Hoebel, E. (1942) The Cheyenne Way, Conflict and Case Law in Jurisprudence Norman, Oklahoma: University of Oklahoma Press, 92-93.

11. National Aboriginal Health Organisation (2008). Cultural Competency and Safety: A Guide for Health Care administrators, providers and educators. Ottawa, Ontario: National Aboriginal Health Organisation

12. Parkhe, A. (1993). Messy research, methodological predispositions, and theory development in international joint ventures. Academy of Management Review, 18, 227-268.

13. Picou, J.S. (2000). The "Talking Circle" as Sociological Practice: Cultural Transformation of Chronic Disaster Impacts. Journal of Clinical and Applied Sociology (2) 77-97.

14. Ramsden, I. (1992). Teaching cultural safety. NZ Nursing Journal, June 21-23.

15. Running Wolf, P., \& Rickard, J.A. (2003). Talking circles: A Native American approach to experiential learning. Journal of Multicultural Counseling and Development, (31) 39-43.

16. Standing Bear, Luther (1933) The Land of the Spotted, Boston, New York: Houghton Mifflin Co. 27.

17. Strauss, A. \& Corbin, J. (1990). Basics of qualitative research: Grounded theory procedures and techniques. Newbury Park: Sage Publications.

18. Sue, V. \& Ritter, L.A. (2007). Conducting Online Surveys. Thousand Oaks, CA: Sage Publications.

19. United Nations. (2000). United Nations millennium declaration Assembly, U. G. (2007). United Nations Declaration on the Rights of Indigenous Peoples. UN: Washington, 12. Department of Economic and Social Affairs. (2009). UN State of the World's Indigenous Peoples.

20. Wilson, D. (2006). The practice and politics of Indigenous health nursing. Contemporary Nurse (22) $\mathrm{x}-\mathrm{xiii}$. 


\section{$\underline{\text { NOTES }}$}

